\title{
Estimates of density and sustainable harvest of the lowland tapir Tapirus terrestris in the Amazon of French Guiana using a Bayesian spatially explicit capture-recapture model
}

\author{
Mathias W. Tobler, Fabrice Hibert, Laure Debeir \\ and CÉCILE RICHARD-HANSEN
}

\begin{abstract}
The Amazonian moist forest, which covers most of French Guiana, is one of the core habitats for the lowland tapir Tapirus terrestris. Tapirs are hunted in French Guiana, although a law introduced in 2011 restricts hunting to one animal per person per hunting trip. We carried out cameratrap surveys in the Nouragues Nature Reserve for 4 years, with the goal of estimating tapir densities in undisturbed conditions and determining sustainable harvest levels for tapirs in French Guiana. We analysed our data with a Bayesian spatially explicit capture-recapture model, with parameter sharing across surveys to improve estimates, and used the model to calculate derived parameters such as maximum sustainable harvest levels. Density estimates for all four surveys were similar and the model indicated a difference in encounter rates for the two camera models used but no difference in encounter rates or home range sizes for males and females or between years. Based on the calculated density of 0.32 tapir $\mathrm{km}^{-2}$ we estimated sustainable harvest levels at 0.009 tapir $\mathrm{km}^{-2}$. Comparing this value to hunting surveys from 11 sites between 1999 and 2006, we found that hunting levels were unsustainable in at least seven villages. We conclude that even the new restrictive hunting law will not prevent overhunting of tapirs in certain areas and thus stronger regulations are needed. However, because of the remoteness of tapir habitat in many parts of French Guiana tapirs are not immediately threatened in the country as a whole.
\end{abstract}

Keywords Amazonian moist forest, Bayesian analysis, camera traps, hunting, Nouragues Nature Reserve, South America, spatially explicit capture-recapture model

This paper contains supplementary material that can be found online at http://journals.cambridge.org

Mathias W. Tobler* (Corresponding author), Fabrice Hibert, Laure Debeir and CÉCILE Richard-Hansen Office National de la Chasse et de la Faune Sauvage, Campus agronomique, BP 376, 97379 Kourou Cedex, France

*Also at: San Diego Zoo Global, Institute for Conservation Research, Escondido, California, USA. Email matobler@gmx.net

Received 1 June 2012. Revision requested 11 September 2012.

Accepted 16 November 2012. First published online 8 October 2013.

\section{Introduction}

The range of the lowland tapir Tapirus terrestris covers 1 large parts of South America, including 11 countries and 25 ecoregions in six biomes (Taber et al., 2009). Circa 51\% of this range is in Amazonian moist forest, of which 95\% is classified as providing medium to high probability of longterm survival for the species (Taber et al., 2009). However, tapir populations are threatened locally by overharvesting and habitat destruction. Tapirs occur in most parts of French Guiana, where 90\% of the land area has intact forest cover and $30 \%$ of the land is within protected areas. The main threat to tapirs in French Guiana is hunting. Unlike other South American countries tapir meat was sold legally in French Guiana until 2007, when a trade ban was introduced (de Thoisy, 2007). In April 2011 tapir hunting was further restricted to one animal per hunter per hunting trip. (Arrêté Préfectoral 583/DEAL, 2011). However, there are still few hunting regulations in French Guiana; hunting permits are not required, hunting is permitted everywhere outside protected areas, and there are hunting seasons or quotas for only a few species. Only a small number of species are completely protected, including the giant otter Pteronura brasiliensis, the black spider monkey Ateles paniscus, the giant anteater Myrmecophaga tridactyla, and all species of felids (Richard-Hansen \& Hansen, 2004). Tapirs are under pressure in areas that are accessible to hunters, who often hunt from boats or pick-up trucks at night. Further pressure comes from an estimated 10,000 illegal gold miners (Moullet et al., 2006), who work in remote areas and depend on hunting for food (Hammond et al., 2007). Scientific data on population densities and sustainable harvest rates are needed to support new restrictions on tapir hunting, which are opposed by local hunters.

There have been few studies of tapir ecology in Amazonia, and most studies have focused on diet and seed dispersal (Bodmer, 1990, 1991; Salas, 1996; Salas \& Fuller, 1996; Herrera et al., 1999; Fragoso \& Huffman, 2000; Montenegro, 2004; Tobler, 2008; Tobler et al., 2010; Hibert et al., 2011). There are only a few estimates of tapir density in the Amazon basin, all based on diurnal line transect data (Janson \& Emmons, 1990; Bodmer et al., 1994; Peres, 2000; Zimmerman et al., 2001; Salovaara et al., 2003; Haugaasen \& Peres, 2005). This scarcity of data is a 


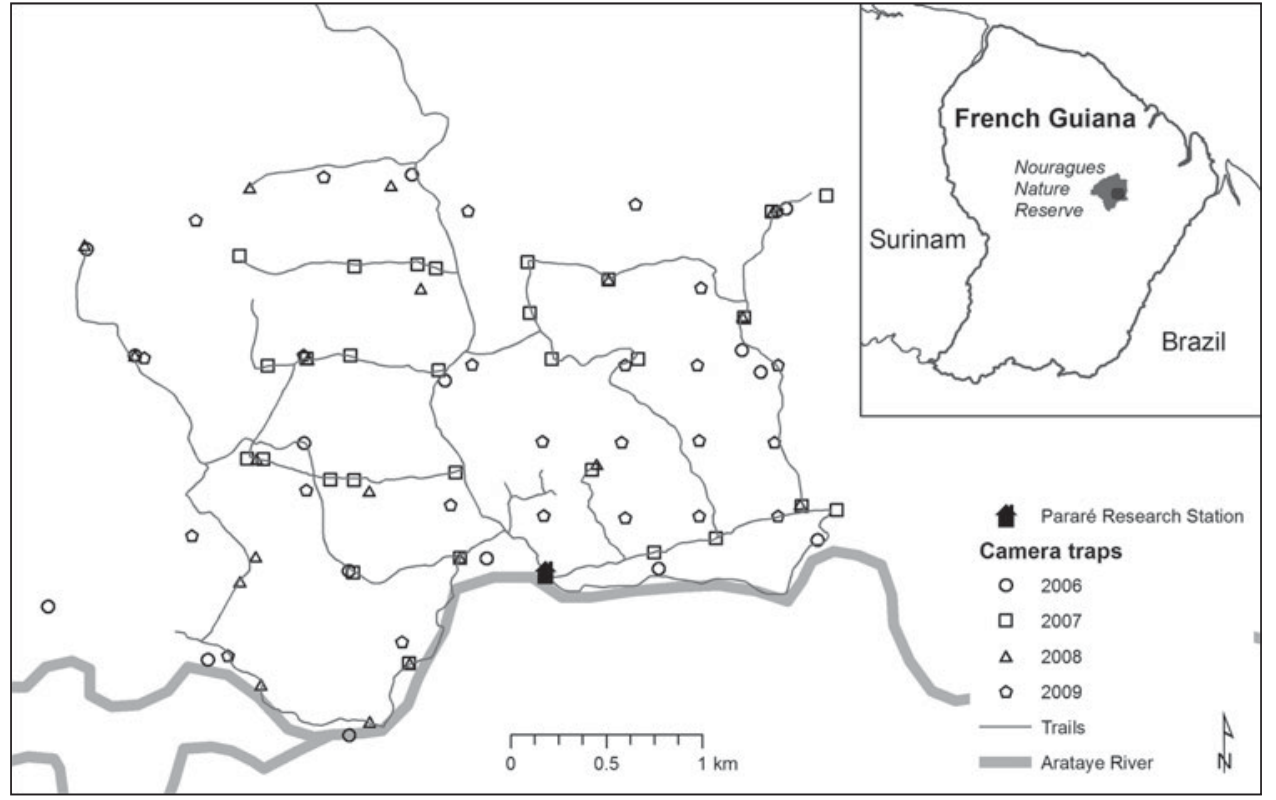

FIG. 1 Camera-trap layout used for a 4-year study of tapir densities in the Nouragues Nature Reserve, French Guiana. reflection of the difficulty of estimating tapir density. Tapirs are predominantly nocturnal (Tobler et al., 2009) and are rarely seen on diurnal transects. Encounter rates recorded by Haugaasen \& Peres (2005) were 0.73 per $100 \mathrm{~km}$ and 0.41 per $100 \mathrm{~km}$ for $1,227 \mathrm{~km}$ and $965 \mathrm{~km}$ of diurnal transects on terra firma and in flood plain forest, respectively. Even on nocturnal transects encounter rates are low, and hundreds if not thousands of kilometres of transects are required for reliable density estimates using the standard distance sampling method (Buckland, 2001; Medici, 2010). Camera traps in combination with capture-recapture models have also been used to estimate tapir densities (Noss et al., 2003, 2012; Trolle et al., 2008; Cruz, 2012). This method relies on the ability of the researchers to identify individual tapirs in photographs. Unlike large cats such as the jaguar, tiger or leopard, where each individual has a unique coat pattern, tapirs have a uniform colour and researchers depend on marks such as ear notches, scars, tail length and shape, sex, and general body size to distinguish individuals (Noss et al., 2003; Trolle et al., 2008; Cruz, 2012). Ideally, individual animals should be independently identified by multiple researchers. Trolle et al. (2008) obtained almost identical results from linetransect and camera-trap data from the same site, indicating that the method can provide reliable density estimates.

We used data from four camera-trap surveys in the Nouragues Nature Reserve in the Amazonian forest of French Guiana to estimate tapir density in an undisturbed population. We used recently developed Bayesian spatially explicate capture-recapture models (Efford, 2004; Royle \& Young, 2008; Efford et al., 2009) and extended them to allow for parameter sharing across 4 survey years and for model selection. We used the estimated tapir density to calculate maximum sustainable harvest levels and compared these to harvest data from 11 sites.

\section{Study area}

The study was carried out at the Parare research station in the $1,000 \mathrm{~km}^{2}$ Nouragues Nature Reserve (Fig. 1), which was designated a protected area by the French government in 1995. The climate is tropical, with a mean temperature of $26^{\circ} \mathrm{C}$ and mean annual rainfall of $3,000 \mathrm{~mm}$. Most of the rain falls during a long wet season from December to August, often interrupted by a short dry period in March.

The vegetation is classified as Guianan moist forest and comprises $>1,200$ known species of angiosperms, dominated by Caesalpiniaceae, Lecythidaceae, Mimosaceae and Sapotaceae (Chave et al., 2001). The terrain is hilly, with elevations of 50-450 $\mathrm{m}$ and a large number of permanent creeks running between the hills. The site contains an intact large mammal fauna, with four of the five ungulate species of Amazonia and the jaguar Panthera onca and puma Puma concolor. The only ungulate species not observed during the study period was the white-lipped peccary Tayassu pecari, which disappeared from most of French Guiana in 2008-2010 (C. Richard-Hansen, pers. obs.). There has been no hunting inside the study area since 1995 but occasionally hunters and illegal gold miners approach to within $10 \mathrm{~km}$ of the study area.

\section{Methods}

\section{Field methods}

Between 2006 and 2009 four camera-trap surveys were carried out along the trail system of the Parare research station, to estimate tapir densities (Table 1). Cameras were set in a more or less regular grid, with distances between cameras varying from 400 to $800 \mathrm{~m}$. This was to ensure that 
TABLE 1 Camera-trap surveys carried out at the Parare site in the Nouragues Nature Reserve in French Guiana to estimate the density of the lowland tapir Tapirus terrestris, with the year, start and end dates, number of survey stations, number of camera days, number of events (i.e. number of independent tapir photographs), capture frequency as number of events per 1,00o camera days, and number and percentage of stations with at least one tapir photograph.

\begin{tabular}{|c|c|c|c|c|c|c|c|}
\hline Year & Start date & End date & Stations & $\begin{array}{l}\text { Camera } \\
\text { days }\end{array}$ & Events & $\begin{array}{l}\text { Capture } \\
\text { frequency }\end{array}$ & $\begin{array}{l}\text { Stations with at least } \\
\text { one photo }(\%)\end{array}$ \\
\hline 2006 & 15 May 2006 & 28 Feb. 2007 & 16 & 4,834 & 41 & 8.5 & $12(75 \%)$ \\
\hline 2007 & 30 Aug. 2007 & 2 Mar. 2008 & 29 & 2,631 & 29 & 11.0 & $10(34 \%)$ \\
\hline 2008 & 20 Aug. 2008 & 10 Apr. 2009 & 17 & 3,768 & 36 & 9.6 & $15(88 \%)$ \\
\hline 2009 & 8 Sep. 2009 & 30 May 2010 & 28 & 6,191 & 60 & 9.7 & $19(67 \%)$ \\
\hline
\end{tabular}

every tapir home range contained at least two cameras, based on a home range size of $1.5-4.0 \mathrm{~km}^{2}$ (Tobler, 2008). The grid covered all major habitat types (creeks, hilltop forest and swamp forest) present in the area. Cameras were placed 50-100 $\mathrm{m}$ off main trails to avoid disturbance by other researchers. From 2006 to 2008 we used CamTrakker Digital cameras (CamTrakker, Georgia, USA), and in 2009 we used a combination of CamTrakker Digital and Reconyx RC55 (Reconyx, Wisconsin, USA) cameras. All cameras were set in pairs at a height of c. $55 \mathrm{~cm}$, to photograph both sides of the tapir. Cameras were in constant operation and were checked approximately once per month to replace batteries and memory cards. In 2007 cameras were operated in two blocks of 15 and 14 stations. In the other years all cameras were operated for the duration of the survey.

\section{Density estimation}

All photographs were imported into Camera Base (Tobler, 2010) for data management. We compiled information on the exact dates that cameras were in the field and when camera failure occurred. Days when cameras were not functioning were masked out in the spatially explicit capture-recapture analyses outlined below. All data were exported from Camera Base in the formats required for data analysis.

Tapirs were independently identified by two members of our research team based on marks such as scars, skin marks, tail length and shape, sex, ear shape and notches, size, shape and size of testicles, and skin folds. Results were then compared, and if there was a disagreement we worked out a consensus. At the end of the process we mapped locations to identify outliers that were far away from other locations and could indicate misidentification. These outliers were double-checked and either confirmed, assigned to a different individual or removed from the analysis. Photographs that could not be attributed clearly to one individual were excluded from the analysis.

The use of camera traps for density estimation was pioneered by Karanth (1995) and Karanth \& Nichols (1998) and has since been applied to a wide range of species. Most studies used the $M_{\mathrm{h}}$ closed capture-recapture model based on the jackknife estimator (Otis et al., 1978) to estimate abundance and apply a buffer around the camera polygon based on the mean maximum distance moved by animals captured more than once, to estimate the effective sampling area and the density. Accurate estimation of this buffer width is difficult, and researchers have questioned whether half or the full mean maximum distance moved gives better density estimates (Soisalo \& Cavalcanti, 2006). More recently developed spatially explicit capture-recapture models estimate animal home range size and density directly, avoiding the problem of which buffer to use (Efford, 2004; Royle \& Young, 2008; Efford et al., 2009). These models have the further advantage that they can incorporate both individual-level covariates such as sex and age class as well as station-level covariates such as road vs trail, camera type and habitat (Sollmann et al., 2011, Tobler et al., 2013), whereas classic capture-recapture models for closed populations only allow individual covariates. Besides the assumption of population closure made by all closedpopulation models, spatially explicit capture-recapture models also assume that activity centres (home range centres) are fixed for the duration of the survey, home ranges are approximately circular and the encounter rate decreases with distance from the activity centre. A half-normal function is generally used to describe the relationship between encounter rate and distance from activity centre. This function uses two parameters: $\lambda_{0}$, the encounter rate at the activity centre, and $\sigma$, a parameter that describes the decline of encounter rates with increasing distance from the activity centre. These models are basically Poisson general linear mixed models, where activity centres are treated as random effects and the encounter rate $\lambda_{0}$ and spatial parameter $\sigma$ are fixed effects. Data augmentation is used to estimate the total number of individuals $n$ in a predefined study area (Royle \& Gardner, 2011).

Our study comprised four surveys in different years at the same site. We were not able to match individual identifications between surveys, and therefore it was not possible to use an open-population model to estimate recruitment, death, immigration and emigration (Gardner et al., 2010). Instead we developed a multi-survey closed spatial model that allows us to share parameters (e.g. $\sigma$ or $\lambda_{\mathrm{o}}$ ) across 
surveys to improve estimates. We used Bayesian variable selection to test whether these parameters were different for male and female tapirs, whether they differed between years, and whether the encounter rate depended on the camera model used. More details on the model can be found in the Appendix.

The spatial model was implemented in WinBUGS (Supplementary Material; Gilks et al., 1994) and run through $R_{2}$ WinBUGS (Sturtz et al., 2005) in $R 2.14$ (R Development Core Team, 2011). We ran four Markov chain Monte Carlo chains, with 15,000 iterations, 10,000 burn-in iterations and a thinning rate of 5 to reduce autocorrelations. For comparison we analysed the data with a classic capture-recapture model, using the secr package (Efford, 2011) in R and calculating a single mean maximum distance moved by combining data from all surveys. See the online supplementary material for more details of the WinBUGS model.

\section{Sustainable harvest estimates}

Bayesian models provide a framework for estimating values and confidence intervals for derived parameters. We used the production model proposed by Robinson \& Redford (1991) to estimate sustainable harvest levels for tapir populations. This model estimates the maximum production $P_{\max }$ of a population, which is expected to occur at 0.6 times the carrying capacity, $K$.

$$
P_{\max }=\left(\lambda_{\max }-1\right) * 0.6 * K
$$

and

$$
\lambda_{\max }=e^{r_{\max }}
$$

where $r_{\max }$ is the population growth rate, which was estimated to be 0.2 for the lowland tapir by Robinson \& Redford (1991). To account for some uncertainty about the $r_{\text {max }}$ parameter in our final estimates we sampled $r_{\max }$ from a normal distribution with a standard deviation of 0.02

$$
r_{\max } \sim \operatorname{Normal}(0.2,0.02)
$$

Because density estimates from undisturbed populations are often used as estimates for carrying capacity (Bodmer \& Robinson, 2004) we assumed that our population was at carrying capacity and that $K=D_{\text {est }}$, the estimated density. We estimated the maximum possible harvest $H_{\max }$ by using a maximum harvest rate of $20 \%$ of the production, as recommended by Robinson \& Redford (1991) for large, longlived animals.

$$
H_{\max }=0.2 * P_{\max }
$$

We compared this to harvest data collected from 11 sites across the country in 1999-2006 (Grenand, 2002; RichardHansen \& Hansen, 2004; C. Richard-Hansen, unpubl. data). At each study site we systematically recorded all hunting trips made by a sample of hunters. Interviewers collected
TABLE 2 Posterior model probabilities (model weights) for the four top-ranking spatially explicit capture-recapture models used to estimate tapir density in French Guiana, based on four cameratrap surveys.

\begin{tabular}{ll}
\hline Model $^{*}$ & Posterior probability \\
\hline$\lambda_{0}(.) \sigma()$. & 0.619 \\
$\lambda_{0}($ Camera $) \sigma()$. & 0.327 \\
$\lambda_{0}($ Sex $) \sigma()$. & 0.019 \\
$\lambda_{0}(.) \sigma(\operatorname{Sex})$ & 0.015 \\
\hline
\end{tabular}

${ }^{*} \lambda_{0}$, encounter rate; $\sigma$, spatial parameter

information daily or weekly. We recorded all animals harvested and information such as the duration and location of the hunting trip, the hunting method and the number of hunters. The duration of data collection for a single study site varied from 77 to 529 days (mean $280 \pm$ SD 117). The location of each animal harvested was mapped on a $5 \times 5 \mathrm{~km}$ grid covering the whole country, and the hunting area was estimated from the number of $25 \mathrm{~km}^{2}$ cells in which at least one harvest was recorded.

\section{Results}

\section{Density estimates}

We obtained 160 independent tapir photographs over 4 years (Table 1). Capture frequencies were similar for all years, as was the number of individuals identified. The number of photographs of each was 1-12; this variation may be a result of varying overlap of different home ranges with the camera grid.

The Bayesian multimodel inference for the spatially explicit capture-recapture model showed very little indication of a difference in the encounter rate $\lambda_{0}$ or the spatial parameter $\sigma$ between male and female tapirs and no difference between years for either parameter (Table 2). There was some indication of a difference in $\lambda_{0}$ for the two camera models, with the encounter rate of the Reconyx camera being twice that of the CamTrakker camera (CamTrakker: $\lambda_{0}=0.0061$, CI 0.0039-0.0086; Reconyx: $\lambda_{0}=0.0093$, CI 0.0062-0.0156). Density estimates were similar for all 4 years, with a mean of $0.32 \pm 0.06$ individuals $\mathrm{km}^{-2}$ (CI $0.21-0.45 \mathrm{~km}^{-2}$ ), and differences between years were within the confidence intervals of the estimates (Table 3 ). The spatial parameter $\sigma$ was estimated to be $923 \pm 90 \mathrm{~m}$ (CI 803-1,074). The Gelman-Rubin statistic (Gelman \& Rubin, 1992) indicated convergence of all chains with $\hat{\mathrm{R}}$ values for all parameters $<1.05$.

Density estimates using the $M_{h}$ jackknife estimator and the mean maximum distance moved were similar to the estimates from the spatially explicit capture-recapture model, whereas estimates using half the mean maximum distance 
TABle 3 Estimations of tapir density in French Guiana using three different capture-recapture models, based on four camera-trap surveys at the Pararé site in the Nouragues Nature Reserve.

\begin{tabular}{lclll}
\hline & & $\begin{array}{l}\text { Density } \\
\text { SECR }^{2} \\
\left(\mathrm{~km}^{-2}\right)\end{array}$ & $\begin{array}{l}\text { Density } \\
\mathrm{MMDM}^{3} \\
\left(\mathrm{~km}^{-2}\right)\end{array}$ & $\begin{array}{l}\text { Density } 1 / 2 \\
\mathrm{MMDM}^{4} \\
\left(\mathrm{~km}^{-2}\right)\end{array}$ \\
\hline 2006 & 9 & $0.26 \pm 0.08$ & $0.23 \pm 0.13$ & $0.43 \pm 0.32$ \\
2007 & 9 & $0.37 \pm 0.11$ & $0.30 \pm 0.19$ & $0.61 \pm 0.50$ \\
2008 & 10 & $0.34 \pm 0.11$ & $0.28 \pm 0.16$ & $0.56 \pm 0.44$ \\
2009 & 10 & $0.33 \pm 0.10$ & $0.32 \pm 0.17^{5}$ & $0.62 \pm 0.47^{5}$ \\
\hline
\end{tabular}

${ }^{1} N_{\text {obs }}$, number of observed individuals

${ }^{2}$ SECR, spatially explicit capture-recapture model

${ }^{3} \mathrm{MMDM}$, closed capture-recapture model using the $\mathrm{M}_{\mathrm{h}}$ jackknife estimator and using the full mean maximum distance moved estimated for all surveys combined

${ }_{1}^{4} / 2$ MMDM, the same model using half the mean maximum distance moved for the buffer

${ }^{5} M_{\mathrm{o}}$ used because $M_{\mathrm{h}}$ produced unrealistically high estimates (1.07 \pm 0.72 and $1.69 \pm 0.653)$

moved were higher. In one case the jackknife estimator produced unrealistically high results and we had to use the $M_{\mathrm{o}}$ model. The mean maximum distance moved for all years combined was $1,790 \pm 899 \mathrm{~m}$.

\section{Sustainable harvest estimates}

Based on our density estimates we calculated a maximum productivity $P_{\max }$ of $0.043 \pm 0.009$ individuals $\mathrm{km}^{-2}$ year $^{-1}$ (CI $0.027-0.062 \mathrm{~km}^{-2}$ year $^{-1}$ ) and a maximum possible harvest $H_{\max }$ of $0.009 \pm 0.002$ individuals $\mathrm{km}^{-2}$ year $^{-1}$ (CI $0.005-0.012 \mathrm{~km}^{-2}$ year $^{-1}$ ) or c. 1 tapir year ${ }^{-1}$ for an area of $100 \mathrm{~km}^{2}$. We found that tapirs were hunted at unsustainable levels in at least seven of the 11 sites studied and harvest rates could be as high as seven times the sustainable level (Table 4).

\section{Discussion}

\section{Tapir density}

We estimated a mean density of 0.32 individuals $\mathrm{km}^{-2}$, which is within the range $0.2-0.6 \mathrm{~km}^{-2}$ reported from Amazonia (Janson \& Emmons, 1990; Bodmer et al., 1994; Peres, 2000; Salovaara et al., 2003; Haugaasen \& Peres, 2005). Density estimates from the Pantanal of Brazil are 0.13-0.58 individuals $\mathrm{km}^{-2}$ (Cordeiro, 2004; Trolle et al., 2008; Desbiez et al., 2010). A density of $0.34 \mathrm{~km}^{-2}$ was estimated for the Atlantic forest of Brazil, based on telemetry data (Medici, 2010), and a camera-trap study in Iguazú National Park in the Atlantic forest of Misiones, Argentina, estimated tapir densities of $0.32 \mathrm{~km}^{-2}$ when a buffer of half the mean maximum distance moved was used and $0.18 \mathrm{~km}^{-2}$ with a buffer of the full mean maximum distance moved (Cruz, 2012). Densities in Urugua-i Provincial Park, an area with medium hunting pressure in the same region, were $0.08 \mathrm{~km}^{-2}$ with half the mean maximum distance moved and $0.05 \mathrm{~km}^{-2}$ with the full mean maximum distance moved (Cruz, 2012). Density estimates from 13 camera-trap surveys in the Bolivian Chaco and Chiquitano dry forest analysed with spatially explicit capture-recapture models were $0.08-0.41 \mathrm{~km}^{-2}$ (Noss et al., 2012). All these density estimates for tapirs fall within $0.1-0.6 \mathrm{~km}^{-2}$ and no clear pattern emerges for different biomes. This indicates that tapirs can adapt to different vegetation types and food resources and maintain similar densities in tropical dry and wet forests. However, lower densities are generally found in areas with hunting pressure or disturbances (Bodmer et al., 1994; Peres, 2000; Cruz, 2012).

Our density estimates were consistent across years, suggesting that camera traps are a suitable tool for obtaining repeatable results for tapir density. Encounter rates and movement did not vary between years. However, encounter rates differed between the two camera models used, with the Reconyx camera having a $1.7 \times$ higher encounter rate than the CamTrakker camera because the CamTrakker has a less sensitive detection circuit and slower trigger speed. There was no difference in movement or encounter rates between males and females. This agrees with findings from two telemetry studies of lowland tapirs that found home range sizes and movement distances varied more between individuals than between the sexes (Tobler, 2008; Medici, 2010).

Density estimates for the classic capture-recapture model with a buffer of the mean maximum distance moved were comparable, although slightly lower than the estimates from the spatially explicit model, but estimates with a buffer of half the mean maximum distance moved significantly overestimated densities, confirming results from a recent simulation study (Tobler \& Powell, 2013). Spatially explicit capture-recapture models have advantages over methods based on closed population capturerecapture and mean maximum distance moved, including the direct modelling of heterogeneity introduced by the spatial distribution of individuals, the estimation of the biologically relevant spatial parameter $\sigma$, and the inclusion of site and individual covariates (Efford et al., 2009; Kery et al., 2011; Royle \& Gardner, 2011; Sollmann et al., 2011). By using Bayesian multimodal inference we can test whether any of the estimated parameters differ by sex, habitat type, year or camera type. These models also allow us to use the exact number of operating days for each station, avoiding bias induced by camera failure (Foster \& Harmsen, 2012) and facilitating analysis in studies where cameras are set using a block design that covers different parts of the study area at different times.

The feasibility of reliably identifying tapirs from cameratrap photos has been questioned by some researchers 


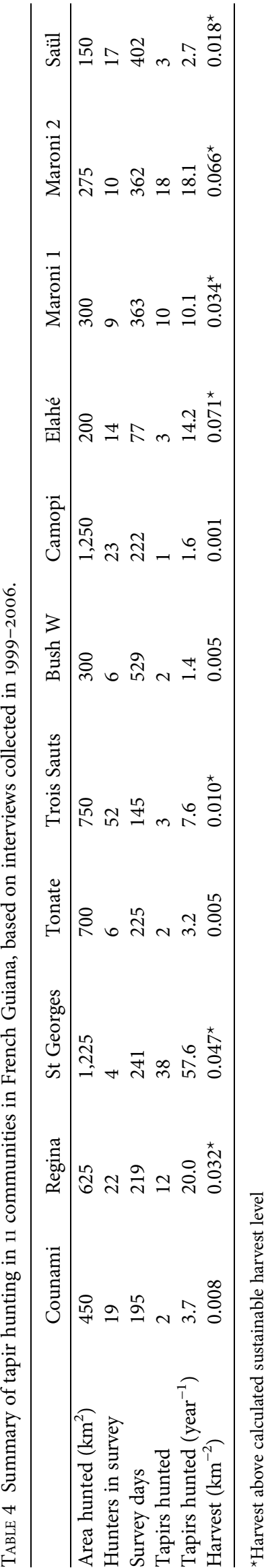

(Oliveira-Santos et al., 2010). The identification of individual tapirs is a time-consuming task and sometimes involves a degree of uncertainty but identifications can be improved when multiple researchers work with the data independently and then integrate their results. We believe that the high variation in the number of individual tapirs identified by 14 researchers in the study by Oliveira-Santos et al. (2010) can be largely attributed to three problems: (1) they used only one flank of the tapir, which makes identification much more difficult, if not impossible in many cases; (2) researchers volunteering to identify tapirs probably spent a few hours working on the photos, compared to the many days we spent on each survey; and (3) results were not discussed and integrated between multiple researchers, a process that can eliminate many errors.

\section{Sustainable harvest estimates}

Given their low population growth rate and density, sustainable harvest levels for tapirs are low, and many studies have shown that tapir harvesting is generally unsustainable. However, because of their size and the quality of the meat, they are often a preferred game species (Bodmer, 1995; Alvard et al., 1997; Bodmer \& Robinson, 2004; RichardHansen \& Hansen, 2004; Naranjo \& Bodmer, 2007; Peres \& Palacios, 2007; Noss \& Cuéllar, 2008). Our estimate of sustainable harvest levels for tapirs in French Guiana is lower than estimates by Robinson \& Redford (1991; $P_{\max }$ of 0.16 individuals km $\mathrm{km}^{-2}$ year $^{-1}$ and $H_{\max } 0.03 \mathrm{~km}^{-2}$ year ${ }^{-1}$, based on a high density of $1.22 \mathrm{~km}^{-2}$ ) and higher than that of Bodmer \& Robinson $\left(2004 ; H_{\max }=0.0055 \mathrm{~km}^{-2}\right.$ ) for the Peruvian Amazon.

Sustainable harvest levels for a specific hunting area should be determined based on the local density of the species. However, obtaining reliable density estimates for tapirs is often not feasible, and therefore a first assessment of hunting sustainability can be based on maximum harvest levels estimated from known densities in the region. If we consider the tapir density in the non-hunted Nouragues Reserve to be representative for French Guiana, we can compare measured harvests at various study sites across the country to a maximum sustainable harvest estimated based on this density. Tapir harvest was beyond the threshold of 0.009 individuals $\mathrm{km}^{-2}$ year $^{-1}$ at seven sites, which is unsustainable. Moreover, these estimates only considered tapirs killed by hunters who voluntarily participated in the surveys, so it is likely that the actual number of tapirs harvested was greater. Furthermore, documented harvesting below the maximum possible level does not necessarily mean that hunting is sustainable in those villages. Low harvest levels could also be an indication of low local density caused by continuous overharvesting (probably the case in Tonate, Counami and Camopi), and more detailed data would be 
needed to evaluate the sustainability of tapir hunting at individual sites. Where a hunted area is surrounded by nonhunted forest, tapir populations often persist at a very low density as a result of immigration of young dispersing animals from the surroundings (Bodmer \& Robinson, 2004; Naranjo \& Bodmer, 2007; Levi et al., 2009). This may occur in many parts of French Guiana where villages are far apart and are bounded by continuous intact forest and is further supported by a very high proportion of young animals killed in some areas with a high hunting pressure (up to $75 \%$ in St George village; C. Richard-Hansen, unpubl. data).

\section{Conclusions and recommendations}

Circa $70 \%$ of French Guiana has low hunting pressure, according to a study that used a human footprint index to quantify human impact (de Thoisy et al., 2010). Areas with the highest pressure are along the coast and in the north, where the human population density and access to the forest by logging roads are highest. In many villages hunters have access to boats with outboard motors, and other vehicles for transportation. This increases the hunting area around a village to up to $1,200 \mathrm{~km}^{2}$, which can theoretically reduce the impact of hunting by spreading it over a larger area (de Thoisy et al., 2009). However, our data showed that larger hunting areas did not necessarily result in lower harvest levels, at least when hunting was for commercial purposes (Table 4, St Georges). Tapirs are mostly hunted along rivers and roads and therefore the impact of hunting might be restricted to a narrow area. However, with the increase of gold mining away from the main rivers, the area affected by hunting is increasing.

Although hunting management in French Guiana has improved, further studies and regulations are needed to reduce the impact of hunting on vulnerable species such as the tapir. The ban on commercial hunting of tapir and the sale of tapir meat, which was introduced in 2007 , reduced the pressure on the species. The tapir harvest data presented here were collected before this regulation took effect, and studies are still ongoing to monitor and compare current harvest levels in the Guiana Amazonian Park and coastal areas.

The recent limit of one tapir per hunter per hunting trip is a step towards more effective regulation, but given that our estimated maximum sustainable harvest level is one tapir per year per $100 \mathrm{~km}^{2}$ it will do little to prevent overharvesting of tapirs. Even if we assume that densities in some parts of French Guiana could be up to twice our observed density, sustainable harvest levels would still be very low, at two tapirs per $100 \mathrm{~km}^{2}$. Completely prohibiting subsistence hunting of tapirs by indigenous communities is neither realistic nor desirable; however, sport hunting of tapirs should be more restricted or banned, as in all other range countries. Educational programmes in communities that regularly hunt tapirs could help create awareness of the vulnerability of the species to overhunting, but the permanent threat represented by illegal gold miners will continue to affect tapir populations. Further studies should be carried out to estimate tapir densities in other parts of French Guiana, both in hunted and non-hunted areas.

\section{Acknowledgements}

We are grateful to The Centre National de Recherche Scientifique-Station des Nouragues and to the National Reserve 'Les Nouragues' for logistical and financial help with the camera-trap study, with particular thanks to Philippe Gaucher and Maël de Winter. We acknowledge Lucille Dudoignon and Cecile Vanpé for their help in collecting camera-trap data. The hunting study was largely funded by the Ministry of Environment: 'Mission pour la creation du Parc de la Guyane' for southern villages and 'Programme Ecosystemes tropicaux' for Regina, St George, Counami and Tonate villages, where data were collected by François Renoux as part of the 'Programme ChasseSilvolab', directed by Pierre Grenand. We thank all the hunters who participated and shared information with us, and the other data collectors, Kamran Khazraie, JeanFrançois Maillard, Mandfred Ulitzka and Aurélie Vinco. We thank Cyril Marmoex, who managed and greatly improved the hunting database and helped with cameratrap surveys, and Beth Gardner and Andy Royle for suggested improvements to the spatially explicit capturerecapture models in WinBUGS, and two anonymous reviewers for their valuable suggestions.

\section{References}

Alvard, M.S., Robinson, J.G., Redford, K.H. \& Kaplan, H. (1997) The sustainability of subsistence hunting in the Neotropics. Conservation Biology, 11, 977-982.

Arrêté Préfectoral 583/DEAL (2011) http://www.gepog.org/sites/ default/files/fichiers/cons_pro/pdf/Arrete_Prefect_quotas_chasse_ 120411.pdf [accessed 26 July 2013].

Bodmer, R. \& Robinson, J.G. (2004) Evaluating the sustainability of hunting in the neotropics. In People in Nature: Wildlife Conservation in South and Central America (eds K.M. Silvius, R.E. Bodmer \& J.M.V. Fragoso), pp. 299-343. Columbia University Press, New York, USA.

BODMER, R.E. (1990) Fruit patch size and frugivory in the lowland tapir (Tapirus terrestris). Journal of Zoology, 222, 121-128.

BODMER, R.E. (1991) Influence of digestive morphology on resource partitioning in Amazonian ungulates. Oecologia, 85, 361-365.

Bodmer, R.E. (1995) Managing Amazonian wildlife - biological correlates of game choice by detribalized hunters. Ecological Applications, 5, 872-877.

Bodmer, R.E., Fang, T.G., Moya, L. \& Gill, R. (1994) Managing wildlife to conserve Amazonian forests - population biology and economic considerations of game hunting. Biological Conservation, $67,29-35$. 
BuckLand, S.T. (2001) Introduction to Distance Sampling: Estimating Abundance of Biological Populations. Oxford University Press, Oxford, UK.

Chave, J., Riera, B. \& Dubois, M.A. (2001) Estimation of biomass in a neotropical forest of French Guiana: spatial and temporal variability. Journal of Tropical Ecology, 17, 79-96.

Cordeiro, J.L.P. (2004) Estrutura e heterogeneidade da paisagem de uma unidade de conservação no nordeste do Pantanal (RPPN SESC Pantanal), Mato Grosso, Brasil: efeitos sobre a distribuição e densidade de antas (Tapirus terrestris) e de cervos-do-pantanal (Blastocerus dichotomus). $\mathrm{PhD}$ thesis. Universidade Federal do Rio Grande do Sul, Porto Alegre, Brazil.

Cruz, M.P. (2012) Densidad, uso del habitat y patrones de actividad diaria del tapir (Tapirus terrestris) en el Corredor Verde de Misiones, Argentina. BSc thesis. Universidad de Buenos Aires, Buenos Aires, Argentina.

De Thoisy, B. (2007) 2007: Two major steps for tapir conservation in French Guiana. Tapir Conservation, 16, 11-12.

de Thoisy, B., Richard-Hansen, C. \& Peres, C.A. (2009) Impacts of subsistence game hunting on Amazonian primates. In South American Primates (eds P.A. Garber, A. Estrada, J.C. Bicca-Marques, E.W. Heymann \& K.B. Strier), pp. 389-412. Springer, New York, USA.

de Thoisy, B., Richard-Hansen, C., Goguillon, B., Joubert, P., Obstancias, J., Winterton, P. \& Brosse, S. (2010) Rapid evaluation of threats to biodiversity: human footprint score and large vertebrate species responses in French Guiana. Biodiversity and Conservation, 19, 1567-1584.

Desbiez, A.L.J., Bodmer, R.E. \& Tomas, W.M. (2010) Mammalian densities in a neotropical wetland subject to extreme climatic events. Biotropica, 42, 372-378.

EFFord, M. (2004) Density estimation in live-trapping studies. Oikos 106, 598-610.

EfFord, M.G. (2011) SECR: Spatially Explicit Capture-Recapture Models. R package version 2.1.o.

Efford, M.G., Dawson, D.K. \& Borchers, D.L. (2009) Population density estimated from locations of individuals on a passive detector array. Ecology, 90, 2676-2682.

Foster, R.J. \& Harmsen, B.J. (2012) A critique of density estimation from camera-trap data. Journal of Wildlife Management, 76, 224-236.

Fragoso, J.M.V. \& Huffman, J.M. (2000) Seed-dispersal and seedling recruitment patterns by the last Neotropical megafaunal element in Amazonia, the tapir. Journal of Tropical Ecology, 16, $369-385$.

Gardner, B., Reppucci, J., Lucherini, M. \& Royle, J.A. (2010) Spatially explicit inference for open populations: estimating demographic parameters from camera-trap studies. Ecology, 91, $3376-3383$.

Gelman, A. \& Rubin, D.B. (1992) Inference from iterative simulation using multiple sequences. Statistical Science, 7, 457-472.

Gilks, W.R., Thomas, A. \& Spiegelhalter, D.J. (1994) A language and program for complex Bayesian modelling. Statistician, 43, $169-177$.

Grenand, P. (2002) La Chasse en Guyane: vers une gestion durable. SILVOLAB - Programme Ecosystèmes Tropicaux, Kourou, French Guiana.

Hammond, D.S., Gond, V., Thoisy, B.D., Forget, P.-M. \& DEDijn, B.P.E. (2007) Causes and consequences of a tropical forest gold rush in the Guiana Shield, South America. AMBIO: A Journal of the Human Environment, 36, 661-670.

Haugaasen, T. \& Peres, C.A. (2005) Mammal assemblage structure in Amazonian flooded and unflooded forests. Journal of Tropical Ecology, 21, 133-145.
Herrera, J.C., Taber, A.B., Wallace, R.B. \& Painter, R.L.E. (1999) Lowland tapir (Tapirus terrestris) behavioural ecology in a southern Amazonian tropical forest. Vida Silvestre Neotropical, 8, 31-37.

Hibert, F., Sabatier, D., Andrivot, J., Scotti-Saintagne, C., Gonzalez, S., Prévost, M.-F. et al. (2011) Botany, genetics and ethnobotany: a crossed investigation on the elusive Tapir's diet in French Guiana. PLoS ONE, 6, e25850.

JANSON, C.H. \& Emmons, L.H. (1990) Ecological structure of the non-flying mammal community at Cocha Cachu Biological Station, Manu National Park, Peru. In Four Neotropical Rainforests (ed. A.H. Gentry), pp. 314-338. Yale University Press, New Haven, USA.

Karanth, K.U. (1995) Estimating tiger Panthera tigris populations from camera-trap data using capture-recapture models. Biological Conservation, 71, 333-338.

Karanth, K.U. \& Nichols, J.D. (1998) Estimation of tiger densities in India using photographic captures and recaptures. Ecology, 79, 2852-2862.

Kery, M., Gardner, B., Stoeckle, T., Weber, D. \& Royle, J.A. (2011) Use of spatial capture-recapture modeling and DNA data to estimate densities of elusive animals. Conservation Biology, 25, 356-364.

Levi, T., Shepard, Jr, G.H., Ohl-Schacherer, J., Peres, C.A. \& YU, D.W. (2009) Modelling the long-term sustainability of indigenous hunting in Manu National Park, Peru: landscape-scale management implications for Amazonia. Journal of Applied Ecology, $46,804-814$.

Medici, E.P. (2010) Assessing the viability of lowland tapir populations in a fragmented landscape. $\mathrm{PhD}$ thesis. University of Kent, Canterbury, UK.

Montenegro, O.L. (2004) Natural licks as keystone resources for wildlife and people in Amazonia. $\mathrm{PhD}$ thesis. University of Florida, Gainesville, USA.

Moullet, D., Saffache, P. \& Transler, A.-L. (2006) L'orpaillage en Guyane française: synthèse des connaissances. Études caribéennes, 4 , 51-57.

Naranjo, E.J. \& Bodmer, R.E. (2007) Source-sink systems and conservation of hunted ungulates in the Lacandon Forest, Mexico. Biological Conservation, 138, 412-420.

Noss, A.J. \& Cuéllar, R.L. (2008) La sostenibilidad de la cacería de Tapirus terrestris y de Tayassu pecari en la tierra comunitaria de origen Isoso: el modelo de cosecha unificado. Mastozoologia Neotropical, 15, 241-252.

Noss, A.J., Cuéllar, R.L., Barrientos, J., Maffei, L., Cuéllar, E., A Rispe, R. et al. (2003) A camera trapping and radio telemetry study of lowland tapir (Tapirus terrestris) in Bolivian dry forests. Tapir Conservation, 12, 24-32.

Noss, A.J., Gardner, B., Maffei, L., Cuéllar, E., Montaño, R., Romero-Muñoz, A. et al. (2012) Comparison of density estimation methods for mammal populations with camera traps in the Kaa-Iya del Gran Chaco landscape. Animal Conservation, 15, 527-535.

Oliveira-Santos, L.G.R., Zucco, C.A., Antunes, P.C. \& Crawshaw, Jr, P.G. (2010) Is it possible to individually identify mammals with no natural markings using camera-traps? A controlled case-study with lowland tapirs. Mammalian Biology - Zeitschrift fur Saugetierkunde, 75, 375-378.

Otis, D.L., Burnham, K.P., White, G.C. \& Anderson, D.R. (1978) Statistical inference from capture data on closed animal populations. Wildlife Monograph, 62.

Peres, C.A. (2000) Evaluating the impact and sustainability of subsistence hunting at multiple Amazonian forest sites. In Hunting 
for Sustainability in Tropical Forests. (eds J.G. Robinson \& E.L. Bennett), pp. 31-56. Columbia University Press, New York, USA.

Peres, C.A. \& Palacios, E. (2007) Basin-wide effects of game harvest on vertebrate population densities in Amazonian forests: implications for animal-mediated seed dispersal. Biotropica, 39, 304-315.

R Development Core Team (2011) R: A Language and Environment for Statistical Computing. R Foundation for Statistical Computing, Vienna, Austria.

Richard-Hansen, C. \& Hansen, E. (2004) Hunting and wildlife management in French Guiana. In People in Nature: Wildlife Conservation in South and Central America (eds K.M. Silvius, R.E. Bodmer \& J.M.V. Fragoso), pp. 400-409. Columbia University Press, New York, USA.

Robinson, J.G. \& Redford, K.H. (1991) Sustainable harvest of neotropical forest mammals. In Neotropical Wildlife Use and Conservation (eds J.G. Robinson \& K.H. Redford), pp. 415-429. University of Chicago Press, Chicago, USA.

Royle, J.A. \& Dorazio, R.M. (2008) Hierarchical Modeling and Inference in Ecology: the Analysis of Data from Populations, Metapopulations and Communities, Academic Press, London, UK.

Royle, J.A. \& Gardner, B. (2011) Hierarchical spatial capture-recapture models for estimating density from trapping arrays. In Camera Traps in Animal Ecology: Methods and Analyses (eds A.F. O’Connell, J.D. Nichol \& K.U. Karanth), pp. 163-19o. Springer, New York, USA.

Royle, J.A. \& Young, K.V. (2008) A hierarchical model for spatial capture-recapture data. Ecology, 89, 2281-2289.

SALAS, L.A. (1996) Habitat use by lowland tapirs (Tapirus terrestris L.) in the Tabaro River valley, southern Venezuela. Canadian Journal of Zoology, 74, 1452-1458.

Salas, L.A. \& Fuller, T.K. (1996) Diet of the lowland tapir (Tapirus terrestris L.) in the Tabaro River valley, southern Venezuela. Canadian Journal of Zoology, 74, 1444-1451.

Salovaara, K., Bodmer, R.E., Recharte, M. \& Reyes, C. (2003) Diversity and abundance of mammals. In Peru: Yavari. Rapid Biological Inventories Report 11 (eds N. Pitman, C. Vriesendorp \& D. Moskovits), pp. 156-164. The Field Museum, Chicago, USA.

Soisalo, M.K. \& Cavalcanti, S.M.C. (2006) Estimating the density of a jaguar population in the Brazilian Pantanal using camera-traps and capture-recapture sampling in combination with GPS radio-telemetry. Biological Conservation, 129, 487-496.

Sollmann, R., Furtado, M.M., Gardner, B., Hofer, H., JÁcomo, A.T.A., Tôrres, N.M. \& Silveira, L. (2011) Improving density estimates for elusive carnivores: accounting for sex-specific detection and movements using spatial capture-recapture models for jaguars in central Brazil. Biological Conservation, 144, 1017-1024.

Sturtz, S., Ligges, U. \& Gelman, A. (2005) R2WinBUGS: a package for running WinBUGS from R. Journal of Statistical Software, 12, $1-16$.

Taber, A., Chalukian, S.C., Altrichter, M., Minkowski, K., Lizárraga, L., Sanderson, E. et al. (2009) El destino de los arquitectos de los bosques Neotropicales: Evaluación de la distribucion y el estado de conservación de los pecaries labiados $y$ los tapires de tierras bajas. Pigs, Peccaries and Hippos Specialist Group (IUCN/SSC) - Tapir Specialist Group (IUCN/SSC) - Wildlife Conservation Society - Wildlife Trust, New York, USA.

Tobler, M.W. (2008) The ecology of the lowland tapir in Madre de Dios, Peru: using new technologies to study large rainforest mammals. PhD thesis. Texas A\&M University, College Station, USA.

Tobler, M.W. (2010) Camera Base Version 1.4. Botanical Research Institute of Texas, Fort Worth, USA.

Tobler, M.W., Carrillo-Percastegui, S.E. \& Powell, G. (2009) Habitat use, activity patterns and use of mineral licks by five species of ungulate in south-eastern Peru. Journal of Tropical Ecology, 25, 261-270.

Tobler, M.W., Janovec, J.P. \& Cornejo, F. (2010) Frugivory and seed dispersal by the lowland tapir Tapirus terrestris in the Peruvian Amazon. Biotropica, 42, 215-222.

Tobler, M.W., Carrillo-Percastegui, S.E., Zúñiga Hartley, A. \& Powell, G.V.N. (2013) High jaguar densities and large population sizes in the core habitat of the southwestern Amazon. Biological Conservation, 159, 375-381.

Tobler, M.W. \& Powell, G.V.N. (2013) Estimating jaguar densities with camera traps: Problems with current designs and recommendations for future studies. Biological Conservation, 159, 109-118.

Trolle, M., Noss, A.J., Cordeiro, J.L.P. \& Oliveira, L.F.B. (2008) Brazilian tapir density in the Pantanal: a comparison of systematic camera-trapping and line-transect surveys. Biotropica, $40,211-217$.

Zimmerman, B., Peres, C.A., Malcolm, J.R. \& Turner, T. (2001) Conservation and development alliances with the Kayapo of southeastern Amazonia, a tropical forest indigenous people.

Environmental Conservation, 28, 10-22.

\section{Appendix}

Bayesian spatially explicit capture-recapture model

Let $y_{i j t}$ be the number of days individual $i$ was detected at camera station $j$ during survey $t$. This was modelled as a Poisson distribution:

$$
y_{i j t} \sim \operatorname{Poisson}\left(\lambda_{0 *} g_{i j}\right),
$$

where $g_{i j}$ is a half-normal detection function based on the distance $d_{i j}$ between the trap $j$ and the activity centre of the individual $i$ :

$$
g_{i j}=\exp \left(-d_{i j}^{2} /\left(2 \sigma_{i t}^{2}\right)\right)
$$

The basic model in the log-linear form is:

$$
\log \left(y_{i j t}\right)=\log \left(k_{j t}\right)+\log \left(\lambda_{0(i j t)}\right)-\left(d_{i j}^{2} /\left(2 \sigma_{i t}^{2}\right)\right)
$$

where $k_{j t}$ is the number of days station $j$ was active during survey $t$. If a station was not active during a survey then $k_{j t}=0$. This allows us to model the number of days each station was functioning during each survey. Incorporating covariates into this model is straightforward. The full model, including covariates for $\lambda_{\mathrm{o}}$ and $\sigma$, is:

$$
\log \left(\lambda_{0(i j t)}\right)=\alpha_{\lambda}+\beta_{\lambda T}[t]+\beta_{\lambda C}\left[\mathrm{cam}_{j}\right]+\beta_{\lambda S}\left[\operatorname{sex}_{i}\right]
$$

and

$$
\log \left(\sigma_{i t}\right)=\alpha_{\sigma}+\beta_{\sigma T}[t]+\beta_{\sigma S}\left[\operatorname{sex}_{i}\right]
$$

$\alpha_{\lambda}$ and $\alpha_{\sigma}$ are the intercepts, $\beta_{\lambda T}$ is a survey effect, $\beta_{\lambda C}$ is a camera effect and $\beta_{\lambda S}$ and $\beta_{\sigma S}$ are sex effects. The variable $\mathrm{cam}_{i}$ is an indicator variable for the camera type used at station $j$ (i.e. 1 for Camtrakker and 2 for Reconyx) and $\operatorname{sex}_{i}$ 
is an indicator variable for sex (1 for male, 2 for female). $\beta_{\lambda T}[1], \beta_{\lambda C}[1], \beta_{\lambda S}[1]$ and $\beta_{\sigma S}[1]$ were set to 0 .

To perform variable selection we included an indicator variable, $w_{j}$, for each covariate (Royle \& Dorazio, 2008). When $w_{j}=1$ the covariate was included in the model; when $w_{j}=0$ it was excluded.

$$
\log \left(\sigma_{i t}\right)=\alpha_{\sigma}+w_{1}^{*} \beta_{\sigma T}[t]+w_{2}^{*} \beta_{\sigma S}\left[\operatorname{sex}_{i}\right]
$$

and

$$
\log \left(\lambda_{0(i j t)}\right)=\alpha_{\lambda}+w_{3}^{*} \beta_{\lambda T}[t]+w_{4}^{*} \beta_{\lambda C}\left[\mathrm{cam}_{j}\right]+w_{5}^{*} \beta_{\lambda C}\left[\operatorname{sex}_{i}\right]
$$

The mean number of times a covariate is included shows the support for that covariate, and posterior probabilities can be calculated for different models (Royle \& Dorazio, 2008). Posterior estimates for $\sigma$ and $\mathrm{D}$ are automatically averaged across models. For a more complete discussion of these spatially explicit capture-recapture models, including the data augmentation used to estimate the total number of individuals $n$, we refer the reader to Royle \& Gardner (2011).

\section{Biographical sketches}

Mathias Tobler has been studying lowland tapirs since 2003 and has a great interest in the spatial and population ecology of large Neotropical mammals. He is constantly working on the development of new analysis techniques for camera-trap data. FABRICE HIBERT's research interests encompass the spatiotemporal organization of animal communities and the modalities and dynamics of resource partitioning, notably in ungulate species. He has extensive field experience in biodiversity assessment and conservation. LAURE DEBEIR studies the ecology of large mammals and amphibian population dynamics in the Neotropics. She is involved in the National Reserves governmental network in French Guiana. Cecile RICHARD-HANSEN has been conducting wildlife research in French Guiana for over 20 years, focusing on hunting impact and sustainability, the ecology of important game species and of threatened species such as the tapir, curassow, and peccary, and habitat-wildlife relationships in tropical forest ecosystems. 